\title{
«VIDA» $\mathrm{Y}$ «SUEÑO» EN ARIOSTO Y LOS ARABES DE JORGE LUIS BORGES
}

Uno de los problemas que han ocupado el quehacer literario de Borges, prácticamente desde sus inicios, es el que ha formulado, desde otro contexto y otra perspectiva, el poeta español Jorge Guillén: «¿Qué hará el autor para convertir las palabras de nuestras conversaciones en un material tan propio y genuino como lo es el hierro o el mármol a su escultor?» ${ }^{1}$. La respuesta de Borges a esta pregunta es mucho más compleja que la simplemente estilística que nos propone Guillén en su libro. Ya en Fervor de Buenos Aires (1923) Borges declara:

$\mathrm{Si}$ en las siguientes páginas hay un verso logrado, perdóneme el lector el atrevimiento de haberlo compuesto yo antes que él. Todos somos unos; poco difieren nuestras naderías, y tanto influyen en las almas las circunstancias, que es casi una casualidad esto de ser tú el leyente y yo el escribidor - el desconfiado y fervoroso escribidorde mis versos («A quien leyere») ${ }^{2}$.

Este pasaje, que en su versión de 1964 se cita con frecuencia en la crítica sobre Borges, no sólo prefigura la famosa noción de «lectura/escritura» que Borges desarrollaría luego en "Pierre Menard» y «Herbert Quain», sino que contiene también una idea que asomará, más explícitamente, años después, en los ensayos y los prólogos de Borges. Nos referimos a la noción del carácter impersonal y comunitario del lenguaje, que figura notablemente en el prólogo de El otro, el mismo (1969), cuando Borges declara que «los idiomas del hombre son tradiciones que

${ }^{1}$ Jorge Guillén, Lenguaje y poesía (Madrid: Alianza Ed., 1971), p. 7.

${ }^{2}$ Citado por Zunilda Gertel, Borges y su retorno a la poesía (New York: The University of Iowa y Las Américas Publ. Co., 1969), p. 60. La versión de 1964 - la actual- reza como sigue: «Si las páginas de este libro consienten algún verso feliz, perdóneme el lector la descortesía de haberlo usurpado yo, previamente. Nuestras nadas poco difieren; es trivial y fortuita la circunstancia de que seas tú el lector de estos ejercicios, y yo su redactor.» 
entrañan algo de fatal. Los experimentos individuales son, de hecho, mínimos, salvo cuando el innovador se resigna a labrar un espécimen de museo, un juego destinado a la discusión de los historiadores de la literatura o al mero escándalo, como el Finnegans Wake o las Soledades» $(O P, \text { p. 114 })^{3}$. Poco tiempo después, en el prólogo a su libro de cuentos El informe de Brodie (1970), Borges reiterará esta idea, pero aminorando su vehemencia con un comentario irónico y contradictorio:

Cada lenguaje es una tradición, cada palabra, un símbolo compartido; es baladí lo que un innovador es capaz de alterar; recordemos la obra espléndida pero no pocas veces ilegible de un Mallarmé o de un Joyce. Es verosimil que estas razonables razones sean un fruto de la fatiga. La ya avanzada edad me ha enseñado la resignación de ser Borges (EIB, p. 10; subrayado nuestro).

He aquí, entonces, la paradoja que preocupa y deleita a Borges: el lenguaje es un sistema de símbolos, tradicional, convencional y común; en él no hay frase, no hay imagen que no haya sido dicha y repetida muchas veces; $\mathrm{y}$, sin embargo, sabemos (o creemos saber) cuándo una página es de Poe y otra es de De Quincey, o cuándo una es de Cervantes y la otra de Unamuno. La exploración y la dilucidación teórica de esta paradoja la ha realizado Borges en los diversos ensayos que ha dedicado al tema de «los clásicos» y a la persona literaria de Whitman, y en relatos como «El inmortal», de El Aleph (1957). Pero nos interesa más, para los efectos de este trabajo, examinar cómo Borges - al igual que cualquier otro escritor digno de recordación- armoniza la dicotomía (ya formulada por Eliot) entre la «tradición y el talento individual» en su práctica literaria. Específicamente, nos interesa estudiar cierto manejo del lenguaje muy frecuente en la escritura de Borges; un manejo mediante el cual Borges se apropia de metáforas o imágenes de uso corriente, dándoles un giro que las hace, si no «nuevas», al menos «distintas» dentro de la tradición literaria a la que pertenecen ${ }^{4}$. En nuestro estudio

${ }^{3}$ Jorge Luis Borges, Obra poética (Madrid: Alianza/Emecé, 1975), p. 114. Todas las citas serán de esta edición. Además, para no abrumar estas notas con citas de Borges, en lo subsiguiente cuando citemos de esta y otras obras de Borges indicaremos entre paréntesis la obra, edición y página, de acuerdo al sistema de abreviaturas siguiente: F: Ficciones (Buenos Aires: Emecé, 1956); EIB: El informe de Brodie (Buenos Aires: Emecé, 1970); D: Discusión (Buenos Aires: Emecé, 1957); HE: Historia de la eternidad (Buenos Aires: Emecé, 1953); OI: Otras inquisiciones (Buenos Aires: Emecé, 1960); OP: Obra poética (Madrid: Alianza/Emecé, 1975).

${ }^{4}$ Emir Rodríguez Monegal, "Símbolos en la obra de Jorge Luis Borges», Studies in Short Fiction, núm. 8, 1971, p. 66. 
nos limitaremos solamente a dos palabras y a un poema de Borges: las palabras «vida» y «sueño» en «Ariosto y los árabes». Hemos escogido este poema, ante todo, por razones pedagógicas (es relativamente largo) y además porque en general la poesía de Borges ha sido menos estudiada, en estos últimos años, que su prosa ${ }^{5}$.

Un último comentario que no podemos dejar de hacer: el alcance de la obra de Borges es todavía mucho más vasto que lo que cubre la propia crítica sobre Borges (la cual es ya bastante voluminosa). Con frecuencia, a lo largo de este ensayo, tendremos la sensación de estar repitiendo cosas que ya han sido dichas sobre Borges, y a veces por el mismo Borges. La crítica sobre Borges que se sitúa en los modestos niveles de este ensayo (y que no se ocupa, digamos, de los problemas epistemológicos que plantea Borges en su obra, o de la cuestión de la «modernidad" de Borges, entre otros temas) tiene que lidiar a cada paso con el malestar de sentirse como algo superfluo, algo tan prescindible para el entendimiento del complejo fenómeno textual que estudiamos bajo la rúbrica de «Borges», como lo sería un cuento o un poema donde se aludiera a Borges. Vaya entonces, como advertencia y explicación de los fines de este trabajo, la siguiente cita de «Magias parciales del 'Quijote'»: «Es verosímil que estas observaciones hayan sido enunciadas alguna vez y, quizá, muchas veces; la discusión de su novedad me interesa menos que la de su posible verdad» $(O I$, p. 65).

\section{«VIDA»Y «SUEÑO» EN OTROS TEXTOS DE BORGES}

Antes de examinar los antecedentes del uso que hace Borges de las palabras «vida» y «sueño» en «Ariosto y los árabes», y del proceso mediante el cual Borges las va convirtiendo en metáforas «nuevas», conviene tener claro cuál es la noción de la metáfora que sustenta Borges en su teoría poética.

En su ensayo sobre el tema de «La metáfora», de $1953^{\circ}$, Borges, apoyándose en Aristóteles, define la metáfora como «la intuición de una analogía entre cosas disímiles»; acto seguido añade una precisión de Middleton Murry, que «exige que la analogía sea real y que hasta enton-

${ }^{5}$ En términos de libros (y no de ensayos, que suelen ser más heterogéneos y difíciles de rastrear) sólo conocemos dos textos que se ocupan específicamente de la poesía de Borges: Guillermo Sucre, Borges, el poeta (Caracas: Monte Avila Eds., 1970), y Zunilda Gertel, Borges y su retorno a la poesía (véase nota 2). La edición original del libro de Sucre es de 1967.

${ }^{6}$ Gertel, p. 90. 
ces no haya sido notada», y continúa diciendo: "Aristóteles, como se ve, funda la metáfora sobre las cosas y no sobre el lenguaje» (HE, p. 70). Ahora bien, para Borges - quien va a fundar su teoría de la metáfora precisamente sobre el lenguaje- las metáforas se dividen en dos clases: las «falsas» y las "verdaderas». Pero ¿en qué reside la «falsedad» de una y la «verdad» de otra? Para responder a esto, tenemos que entender que el pensamiento de Borges sobre la metáfora se desplaza —pongámoslo así- a lo largo de dos ejes: uno de reflexión sobre el lenguaje y otro de adhesión personal a los principios «clásicos» de la escritura. Por el eje linguíístico, tendríamos que observar que nociones como las de «verdad» o «falsedad», o aun de «realidad» (pensemos en la cita de Middleton Murry), aplicadas al lenguaje, sólo tienen sentido en cuanto se apoyen en la convención de determinado grupo de hablantes; las metáforas, como bien observa Borges, no son objetos «sólidos», «reales»; son formaciones linguíisticas, y su posible «realidad» o «verdad» o «falsedad" dentro de una lengua depende del juicio colectivo de los hablantes. Por otra parte, el notorio «clasicismo» de Borges lo lleva a sustentar la creencia — característica, según Borges, de los clásicos- «de que una vez fraguada una imagen, ésta constituye un bien público» $(D$, p. 70). La metáfora «verdadera» sería, entonces, aquella que se nos propone (y que aceptamos) como evidente e incluso inevitable, porque se conforma a las exigencias de la convención social y de la tradición. Metáforas "verdaderas» serían, por ejemplo, las que comparan la vida con un río, la muerte con el mar, la vida (y la muerte) con un sueño - volveremos, como es natural, sobre esto-, las mujeres con las flores, y así sucesivamente. Con las metáforas «falsas» sucedería el proceso contrario; serían comparaciones no-evidentes, contrarias a la tradición y a la convención, y difíciles de convencionalizar. Las kenningar son un buen ejemplo en este sentido, pues aunque eran sin duda metáforas convencionales entre los pueblos nórdicos, no señalaban, sin embargo, comparaciones evidentes, sino que con frecuencia cumplían la función inversa de hacer extraño lo evidente:

El signo pierna del omoplato - apunta Borges- es raro, pero no es menos raro el brazo del hombre. Concebirlo como una vana pierna que proyectan las sisas de los chalecos y que se deshilacha en cinco dedos de penosa largura es intuir su rareza fundamental. Las kenningar nos dictan ese asombro, nos extrañan del mundo (HE, p. 65).

Un examen más detallado de la teoría de la metáfora en Borges rebasaría los límites de este ensayo. Por lo pronto, conviene tener en mente que la metáfora que «vale la pena inventar», según Borges, es aquella que 
codifica una experiencia común a todos, pero que quizá no ha sido puesta en evidencia antes; aquella que armoniza, en un acto de reconocimiento compartido, la experiencia individual del escritor y del lector.

Antes de pasar a nuestro análisis debemos advertir que nos interesa poco, para nuestros efectos, reconstruir cronológicamente las vicisitudes de la metáfora vida/sueño en la obra de Borges. En cambio, lo que nos proponemos hacer aquí es tomar en cuenta la mecánica de lectura de ese texto coherente y unitario en que Borges ha convertido su otrora (verosímilmente) abigarrada obra poética. Como se sabe, desde que en 1943 la editorial Losada sacó a la luz los Poemas (1922-1943) de Borges, éste ha aprovechado las sucesivas reediciones para ir ejerciendo su «perversa costumbre de falsear y magnificar» (EH, p. 70), y ha reescrito, omitido y organizado sus poemas y prólogos hasta hacer de ellos «un orbe autónomo de corroboraciones, de presagios, de monumentos» (como dice del Ulysses de Joyce en «El arte narrativo y la magia», $D$, p. 91). En el prólogo a la sección de Fervor de Buenos Aires de la edición conjunta Alianza/Emecé de 1975 (que estamos usando), Borges nos da un tenue indicio de lo que ha hecho con su poesía: «He mitigado sus excesos barrocos, he limado asperezas, he tachado sensiblerías y vaguedades» $\left(O P\right.$, p. 9) ${ }^{7}$. Hemos procurado, por tanto, leer la Obra poética tal y como Borges, mediante su constante intromisión en las sucesivas reediciones de su obra (acto paradójicamente «personal» en un hombre que dice creer en la «impersonalidad» de la literatura), ha querido que se lea: con la plena conciencia de que es un artificio diseñado para burlar al tiempo y a los filólogos.

Siguiendo, entonces, el orden de lectura que la Obra poética de 1975 nos propone, encontramos que la primera mención de la metáfora vida/ sueño aparece en un poema de Fervor de Buenos Aires («Amanecer»):

¡Hora en que el sueño pertinaz de la vida corre peligro de quebranto...! (OP, p. 38).

Aquí la metáfora cumple una función bastante tradicional, aunque su contexto (las alusiones a Schopenhauer y a Berkeley en el mismo poema) sea bastante novedoso; no obstante, como en la obra de Calderón, el referente de la metáfora todavía se mueve en un plano de reflexión meta-

${ }^{7}$ Nos resultó interesante consultar a este respecto a lista de reediciones y revisiones de la poesía de Borges ("Contents of the Principal Editions of Borges' Poetry») que aparece al final de la edición en inglés de la poesía escogida de Borges. Jorge Luis Borges, Selected Poems (1923-1967), ed., introducción y notas de Norman Thomas di Giovanni (Nueva York: Delacorte Press, 1972), p. 313-324: 
física sobre la «realidad»: basta quizá con recordar aquella escena en la que Basilio le advierte al recién liberado Segismundo que no abuse de sus poderes, porque aún puede estar soñando. Responde Segismundo:

$$
\begin{aligned}
& \text { ¿Que quizá soñando estoy } \\
& \text { aunque despierto me veo? } \\
& \text { No sueño, pues toco y creo } \\
& \text { lo que he sido y lo que soy }{ }^{8} \text {. }
\end{aligned}
$$

Después de esta primera aparición de la metáfora no volveremos a encontrar los dos términos, «vida» y «sueño», unidos en un mismo verso hasta la estrofa final de «Ariosto y los árabes», que examinaremos oportunamente. Lo que observaremos hasta llegar a "Ariosto y los árabes», en cambio, es el proceso mediante el cual Borges va sigilosamente desmontando y modificando los referentes de la metáfora, hasta convertir los términos «vida» y «sueño», por separado, en metáforas cuyos referentes poco o nada tienen que ver con la «realidad». Veamos primero lo que sucede con la palabra «vida». En los dos poemas recogidos bajo el título de «Muertes de Buenos Aires», cuando se alude a la «vida», se hace todavía bajo la advocación del uso tradicional de la palabra, un uso que podemos catalogar de «metafísico»:

y convencido de corruptibilidad el suburbio apura su caliente vida a tus pies...

La muerte es vida vivida,

la vida es muerte que viene (OP, p. 102).

${ }^{8}$ Pedro Calderón de la Barca, La vida es sueño (Madrid: Espasa-Calpe, 1967), p. 157. Quizá para Calderón, preocupado más por los problemas de la predestinación y el libre albedrío, esta metáfora no significó más que la repetición de una doctrina religiosa acerca del carácter ilusorio del mundo que todos en su época reconocian y aceptaban. Según apunta el sacerdote Félix G. Olmedo, S. J., en una curiosa monografía (escrita en buena medida contra el libro de Arturo Farinelli) sobre Las fuentes de «La vida es sueño»: «En tiempo de Calderón, la idea de que la vida es como un sueño y de que todas las grandezas de este mundo son como soñadas estaba en el ambiente. Llenos estaban de ella los abecedarios y castillos espirituales, los espejos del alma, las escuelas de perfección, los caminos del espíritu, las guías de pecadores, los memoriales de la vida cristiana, los vergeles de oración, los tratados de la vanidad y menosprecio del mundo y, en general, todos los libros espirituales y devotos» (Las fuentes de "La vida es sueño», Madrid: Editorial Voluntad, 1928, pp. 15-16). Pero lo cierto es que, después de la relectura de Calderón hecha por los románticos a principios del siglo XIX -relectura hecha en consonancia con la filosofía idealista-, el primer impulso del lector moderno al leer el texto de Calderón es de interpretarlo como si se tratara de un discurso metafísico sobre la naturaleza del mundo «real». Véase Manuel Durán y Roberto González Echevarría, Calderón y la crítica: historia y antología (Madrid: Gredos, 1976), pp. 38-60. 
Más adelante, ya en $E l$ otro, el mismo, la «vida» se sitúa en un contexto similar al de la metáfora vida/sueño que ya vimos, pero esta vez sin que esté en relación exclusiva con el «sueño»:

A las sombras, los sueños y las formas

Que tejen y destejen esta vida (OP, p. 141).

La imagen de la vida como un tejido, o como un hilo, es una imagen clásica (basta pensar en las tres Parcas); pero a lo que nos remite este verso, ante todo, es a la visión de la "vida» como un artificio, una producción de «las sombras, los sueños y las formas». Es la visión que se expresa con mayor lucidez en el poema «Susana Soca», cuando dice:

\author{
Le placía \\ Perderse en la compleja melodía \\ $O$ en la curiosa vida de los versos (OP, p. 165).
}

Aquí tenemos, entonces, una ecuación metafórica que habrá de reaparecer en la poesía posterior de Borges: «vida»-literatura. No nos es posible precisar más la relación de la «vida» con alguna cualidad particular de la literatura, concretamente en el acto de leer o en el de escribir. De hecho, nos parece que Borges utiliza este término (como tantos otros) con una deliberada vaguedad; de todos modos, si la «vida» puede identificarse con la literatura, su alcance de significados posibles debe incluir necesariamente los actos de leer y de escribir, que, como Borges ya ha planteado en «Pierre Menard» y «Herbert Quain», son fundamentalmente la misma cosa.

Pasando a examinar ahora la palabra «sueño», lo primero que observamos es que se menciona mucho más a lo largo del texto que la palabra «vida». Es evidentemente una palabra favorita de Borges, quizá, entre otras razones, por las numerosas alusiones que el lenguaje ya ha codificado en ella, desde Calderón hasta Sigmund Freud. Como hizo con el término «vida», Borges procederá a transformar el referente de la palabra «sueño» dentro del sistema coherente que es su poesía. Las primeras menciones del «sueño» en la Obra poética están todavía enmarcadas en la definición más o menos tradicional del sueño, como la que da, allá para 1611, Sebastián de Covarrubias y Orozco en su Tesoro de la lengua castellana o española:

Son ciertas fantasías que el sentido común rebuelve cuando dormimos, de las cuales no hay que hazer caso, y solos aquellos sueños tienen alguna apariencia de verdad, por los cuales los médicos juzgan el 
humor que predomina en el enfermo, y no entran en esta cuenta las revelaciones santas y divinas, hechas por Dios a Joseph y a otros santos.

Nos duele sostener esa luz tirante y distinta esa alucinación que impone al espacio

el unánime miedo de la sombra

y que cesa de golpe

cuando notàmos su falsía,

como cesan los sueños

cuando el soñador advierte que duerme ( $O P$, p. 36).

Todavía no hay nada, en los anteriores versos, que modifique sustancialmente el sentido de la palabra «sueño», aunque el contexto en que aparece es el de una comparación implícita entre el carácter ilusorio de la vida y los sueños. Ahora bien: casi de repente, y sin previo aviso, nos encontramos con la dedicatoria de $E l$ otro, el mismo, donde aparece la siguiente oración: "A izquierda y a derecha, absortos en su lúcido sueño, sé perfilan los rostros momentáneos de los lectores, a la luz de las lámparas estudiosas, como en la hipálage de Milton» (OP, p. 117). De un plumazo, por decirlo así, se nos establece la ecuación metafórica «sueño»: lectura (o literatura), que va a reaparecer a lo largo de El otro, el mismo. La transición, que también en el caso de la palabra «vida» parece abrupta, no lo es si tomamos en cuenta los textos en prosa que Borges estuvo escribiendo en los años que mediaron entre Cuaderno San Martín (1929) y -fijemos la fecha un tanto arbitrariamente- 1960, que es cuando Emecé publica $E l$ hacedor, donde aparece el grueso de los poemas que van a constituir $E l$ otro, el mismo, incluyendo "Ariosto y los árabes" ". De todos esos numerosos escritos vale la pena apuntar unọ donde la formulación «sueño»-literatura aparece con claridad; en su ensayo «El escritor argentino y la tradición», Borges concluye diciendo: "Creo que si nos abandonamos a ese sueño voluntario que se llama la creación artística, seremos argentinos y seremos también buenos y tolerables escritores» $(D, \mathrm{p}:$ 162). La «creación artística», escribir, es un "sueño voluntario»: ¿no es eso lo que hace, también, el protagonista de «Las ruinas circulares» en Ficciones (1956)?

El propósito que lo guiaba no era imposible, aunque sí sobrenatural. Quería soñar un hombre: quería soñarlo con integridad minuciosa e imponerlo a la realidad. Ese proyecto mágico había agotado el espacio entero de su alma; si alguien le hubiera preguntado su propio nom-

\footnotetext{
${ }^{9}$ Borges, Selected Poems, pp. 315-319.
} 
bre o cualquier rasgo de su vida anterior, no habría acertado a responder $(F$, p. 60$)$.

Al hipotético lector que conociera bien la obra en prosa de Borges en el momento de leer por primera vez "Ariosto y los árabes», las formulaciones que allí se hacen no le hubieran parecido muy extrañas, y quizá hasta le hubieran despertado las mismas resonancias que nos han llevado a releer el ensayo y el cuento de Borges que ya hemos citado. De todas formas, en los poemas anteriores de El otro, el mismo se utiliza bastantes veces la palabra «sueño» como metáfora de la literatura, de modo que al llegar a «Ariosto y los árabes» (p. 186) ya nos encontramos perfectamente situados en la red de resonancias. Anotemos simplemente algunos ejemplos: "por este soñoliento enlace de numéricas palabras» («Poema del cuarto elemento», p. 132); "A unos ojos sin luz que sólo pueden / Leer en las bibliotecas de los sueños» («Poema de los dones», p. 153); «Claudio, rey de una tarde, rey soñado» («Los espejos», p. 161; se alude, por supuesto, al Hamlet de Shakespeare); «Este será como los otros una forma / De mi sueño, un sistema de palabras / Humanas» («El otro tigre», p. 174).

\section{«VIDA» Y «SUEÑO» EN «ARIOSTO Y LOS ÁRABES»}

Nadie puede escribir un libro. Para

Que un libro sea verdaderamente,

Se requieren la aurora y el poniente,

Siglos, armas y el mar que une y separa ( $O P$, p. 186, vs. 1-4).

De entrada sabemos que el asunto del poema no es - si se quierelírico, sino, evidentemente, de teoría literaria. Borges vuelve a hacer en español, y con mayor felicidad, algo que no se intentaba desde que Bello escribió su neoclásica "Alocución a la poesía»; otra afinidad posible la podríamos señalar con el «Essay on Criticism» de Pope; en ambos casos se trata de un discurso crítico formulado como un discurso poético. Las diferencias, claro está, son más que los parecidos.

Ahora bien: de repente, en este poema sobre un poema nos encontramos con una alusión a los sueños:

Así lo pensó Ariosto, que al agrado

Lento se dio, en el ocio de caminos

De claros mármoles y negros pinos,

De volver a soñar lo ya soñado (vs. 5-8). 
Ariosto «sueña» al Orlando Furioso; traducir: Ariosto escribe. O, para ser más precisos, Ariosto reescribe: "volver a soñar lo ya soñado» (v. 8). Inmediatamente, el poema entra en consideraciones de índole crítica sobre la intertextualidad del Orlando; el Orlando es un «tejido de sueños»:

Escoria de los sueños, indistinto

Limo que el Nilo de los sueños deja,

Con ellos fue tejida la madeja

De ese resplandeciente laberinto (vs. 49-52).

Pero los «sueños» que Borges enumera no son sino textos de la literatura europea clásica y medieval: la Chanson de Roland, las leyendas del rey Arturo, la búsqueda del Santo Grial, el mito del Pegaso. «Sueños»: textos («soñar»: «tejer»: escribir); la metáfora, entre otras cosas, va minando la noción filológica del «origen» de un texto. Todos «soñamos»; todos, en acto o en potencia, emitimos textos: Ariosto no es fuente, sino confluencia, intersección, encrucijada de textos ajenos. Pero, en tanto y en cuanto no lo sospechemos, en tanto y en cuanto lo aceptemos sueño (esta vez sin las comillas que indican la metáfora), el Orlando nos parecerá tan encantador y autosuficiente en su belleza como un diamante «en el que un hombre / Puede perderse venturosamente» (vs. 53-54).

Implícita en este argumento está la noción del texto como una entidad orgánica, dotada de una suerte de «vida» ilusoria, dependiente de la lectura y de la escritura para su existencia; recordemos «la curiosa vida de los versos» («Susana Soca», OP, p. 165). Los versos tienen su «vida», y se la damos al leerlos y/o escribirlos; pero por ser una vida que otorgamos (y que, en consecuencia, podemos revocar), es también una "vida» en cierto modo «falsa», ilusoria. Así podemos entender, en términos más «textuales», la segunda estrofa del poema:

Ni el amor ignoró [Ariosto] ni la ironía

Y soñó así, de pudoroso modo,

El singular castillo en el que todo

Es (como en esta vida) una falsía (vs. 41-44).

La «vida» a que se refiere el último verso no es (necesariamente) la de Borges o la nuestra, sino la «curiosa vida de los versos» que ya hemos mencionado. Como se ve, Borges va preparándonos para el modesto asombro del final de su poema. Pero aún nos falta por examinar otro aspecto de los «sueños»: su propensión a ser reemplazados por otros «sueños».

Las mil y una noches, «que vagos rostros con turbante / Soñaron, se 
adueñó del Occidente» (vs. 80-81). ¿Cómo ocurrió esto? Borges no pretende darnos toda la respuesta, pero nos la sugiere; el Orlando fue «Por islámicas artes reducido / A simple erudición, a mera historia» (versos 86-87). En lo que a las «islámicas artes» se refiere, conviene recordar un hecho que ya Borges destacó en su relato «La busca de Averroes» de El Aleph (1961), que posiblemente redactara no mucho después de «Ariosto y los árabes»: la Poética de Aristóteles, el libro que sistematiza por primera vez la «crítica» literaria en Occidente, fue diseminado en la Europa medieval a través de la versión arábiga atribuida a Averroes ${ }^{10}$. También la crítica literaria, además de la cuentística maravillosa de Las mil y una noches, es un «arte islámico». Arte que resulta en perjuicio del Orlando, porque en la búsqueda erudita de «fuentes» se despliega la intertextualidad de la obra, y ya no es posible volver a leer el poema de Ariosto con la misma ingenuidad de Milton, que «pudo llorar de Brandimarte / El fin y de Dalinda la zozobra» (vs. 59-60). Rota entonces la ilusión («ese enorme diamante», v. 53) y suplantada por otra, el Orlando «Está solo, soñándose» (v. 87); aquí la palabra sueño, por su contexto, sugiere tanto la lectura -el Orlando «se está leyendo» a sí mismo; es decir, nadie más lo lee- como el sueño: el libro está, metafóricamente, «dormido», o quizá incluso «muerto», pues nadie le da «vida» con su lectura. (Aquí podríamos señalar una observación que Borges hace en el prólogo de Elogio de la sombra, más adelante en el mismo volumen de la Obra poética: «Un volumen, en sí, no es un hecho estético, es un objeto físico entre otros; el hecho estético sólo puede ocurrir cuando lo escriben o lo leen», p. 308.)

«Ariosto y los árabes» termina con la metáfora vida/sueño, que ahora cobra un nuevo referente - la teoría literaria-y un nuevo significado:

En la desierta sala el silencioso

Libro viaja en el tiempo. Las auroras

Quedan atrás y las nocturnas horas

Y mi vida, este sueño presuroso (vs. 93-96).

«Mi vida», ya lo sospechamos, no es (meramente) la vida de Borges, sino la «vida» del poema mismo, su existencia como poema, como «hecho estético», que no es otra cosa que un «sueño presuroso», es decir, una lectura/escritura breve: después de todo, «Ariosto y los árabes» no es un poema tan largo como el Orlando. Podrá objetarse que ésta es una interpretación demasiado prosaica (y qué interpretación de un poema no

10 Allan H. Gilbert, Literary Criticism: Plato to Dryden (New York: American Book Co., 1940), pp. 63-65. 
lo es), pero también tiene algo de irónico; la posible perduración del Orlando está sujeta a los azares de esa lectura «presurosa» que hacemos del poema de Borges: porque está claro que leyendo "Ariosto y los árabes» leemos también - un poco- al poema de Ariosto.

\section{CONCLUSIONES}

A través de este somero examen de "Ariosto y los árabes» esperamos haber puesto en claro el funcionamiento de un rasgo de la escritura de Borges, que es también (inseparablemente) un rasgo de nuestra lectura de Borges. Borges convierte una de las metáforas más viejas y ricas del idioma español (y de la cultura europea en general) en otra metáfora igualmente rica y quizá más verdadera. Hoy día, después del ocaso de Hegel, creer que la vida puede ser un sueño no pasa de ser un disparate o, lo que es peor, una cursilería; en cambio, creer que nuestra vida es un constante acto de lectura, de desciframiento de signos, es algo que hoy, después de Cassirer, Lévi-Strauss y Derrida, nos parece un poco más razonable.

Yale University.

Aníbal GonZÁlez 